ИЗВЕСТИЯ АКАДЕМИИ НАУК ЭСТОНСКОИ ССР. ТОМ 26 ХИМИЯ * ГЕОЛОГИЯ. 1977, № 4

\title{
ХАРАКТЕРИСТИКА ОРГАНИЧЕСКОГО ВЕЩЕСТВА ОЛЕНЁКСКОГО ГОРЮЧЕГО СЛАНЦА
}

Восточная Сибирь богата горючими сланцами, которые, как и эстонские горючие сланцы, относятся к нижнему палеозою [1,2]. Они малоизучены, промышленно не перерабатываются, и поэтому в литературе нет данных о структуре керогена этих сланцев.

Нами проведено исследование пробы сланца, отобранной из обнажения в 18 км от поселка Оленёк после снятия поверхностного слоя и предоставленной геохимическим отделом Восточной Сибири ВНИГРИ. Сланец принадлежит к амгинско-майскому ярусу куонамской свиты, возраст - средний кембрий $\left(\mathrm{C}_{\mathrm{M}_{1-2}}\right)$.

Приводится характеристика органического вещества этих сланцев, установленная термической деструкцией. Органическое вещество этих сланцев состоит из растворимого битумоида и нерастворимого керогена, которые анализировались раздельно для установления их общих структурных элементов и генетической связи. Битумоид был разделен методом препаративной тонкослойной хроматографии на группы соединений, состав которых исследовался методом газовой хроматографии. Высокомолекулярная часть битумоида (асфальтены) и дебитуминизированный кероген подвергались термодеструкции.

Примененная методика тонкослойной и газовой хроматографии описана в литературе [3]. Для анализа использовали аппарат «Хром-4» с параллельными колонками и пламенно-ионизационными детекторами.

Технический состав сланца: влаги $W^{a}-3,33$, золы $A^{c}-67,2$, минеральной $\left(\mathrm{CO}_{2}\right)^{c}-2,2$, общей серы $S^{c}-0,88$, условного органического вещества - 30,6\% на сухое вещество. Путем экстракции сланца смесью метанола и бензола $(1: 3)$ в аппарате Сокслета в течение 50 из него извлекли битумоида $0,58 \%$ и последующей экстракцией эфиром - еще $0,05 \%$. Эфирный экстракт отличается от спирто-бензольного экстракта более высоким содержанием углеводородов и их разнообразным составом.

Битумоид состоит в основном из высокомолекулярных гетеросоединений (таблица). н-Парафины (хроматограммы парафинов представлены на рис. 1) характеризуются бимодальным концентрационным распределением, основная их часть является низкокипящими, максимальную концентрацию имеет $\mu-\mathrm{C}_{11}$. В высококипящей области преобладают «нечетные $н$-парафины» $\mathrm{C}_{27}, \mathrm{C}_{29}$ и $\mathrm{C}_{31}$. Присутствуют также изопреновые углеводороды $i-C_{11}-i-C_{20}$, причем низкокипящие представители в значительных количествах. Остальные группы битумоида содержали 
Групповой состав битумоида и смолы полукоксования

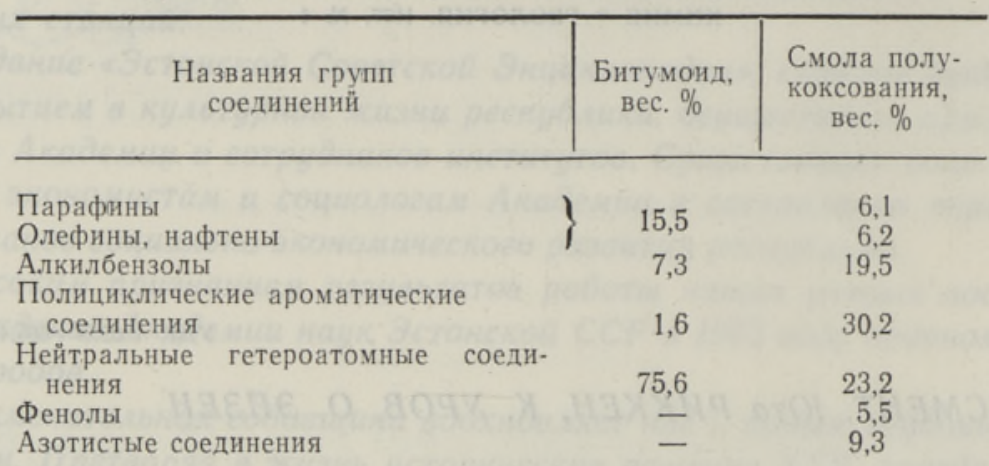

очень мало летучих соединений. Гетеросоединения (асфальтены) подвергались термолизу в стеклянной трубке при $400-500^{\circ} \mathrm{C}$, пиролизат разделяли тонкослойной хроматографией. Состав углеводородов пиролизата (рис. 1, II) отличается от состава несвязанных углеводородов наличием более длинных углеродных цепей (до $\mathrm{C}_{23}$ ); основные представители изопреноидов - $i-\mathrm{C}_{19}$ и $i-\mathrm{C}_{20}$. В высококипящей области присутствуют углеводороды нелинейного строения, которые имеются также в диктионемовых сланцах.

Пиролизат асфальтенов содержит мало ароматических структур. На хроматограммах сильно адсорбирующихся групп выявляются два гомологических ряда с иным, чем у н-алкилкетонов (присутствующих обычно в подобных пробах) относительным расположением их. Кроме карбонильных, могут иметь место другие функциональные группы. Отмечено ступенчатое изменение концентрации членов указанных гомологических рядов. Пиролизат богат алифатическими структурами, ненасыщенных соединений мало, что указывает на ароматическую структуру основной массы асфальтенов.

Основное количество органического вещества сланца сосредоточено в нерастворимом керогене, который подвергался полукоксованию по ГОСТ 3168-66. Выход смолы составляет 4,6, воды - 5,2, кокса - 84,0, газа и потерь $-6,4 \%$ (на сланец). На условное органическое вещество приходится смолы 15,5 , воды разложения 17,4\%. Плотность смолы 0,9716 , показатель преломления 1,555. Выход смолы весьма низок, по литературным данным ['] $30-35 \%$ на органическое вещество.

На хроматограмме суммарной смолы полукоксования, как и в случае диктионемовых сланцев, наблюдается множество пиков моно- и бициклических ароматических углеводородов. Парафины и олефины (рис. 1 , III) имеют такое же концентрационное распределение по длине углеродной цепи, как и основная часть углеводородов битумоида. Олефинов образуется немного больше, чем обычно из керогенов коллоальгинитового типа, относительно много 2-олефинов, мало их с центральным положением двойной связи. Изопреновые углеводороды отсутствуют.

Ароматические углеводороды образуют наиболее характерные группы исследованной смолы (рис. 2 и 3). По сравнению с диктионемовыми сланцами у алкилбензолов больше ортодиалкилструктур и меньше метаизомеров. В конце хроматограммы видны небольшие группы, компоненты которых принадлежат к нескольким гомологическим рядам. Эти соединения являются алкилбензолами $\mathrm{C}_{14}-\mathrm{C}_{17}$, молекулы которых имеют длинные боковые углеродные цепи. Такие группы 

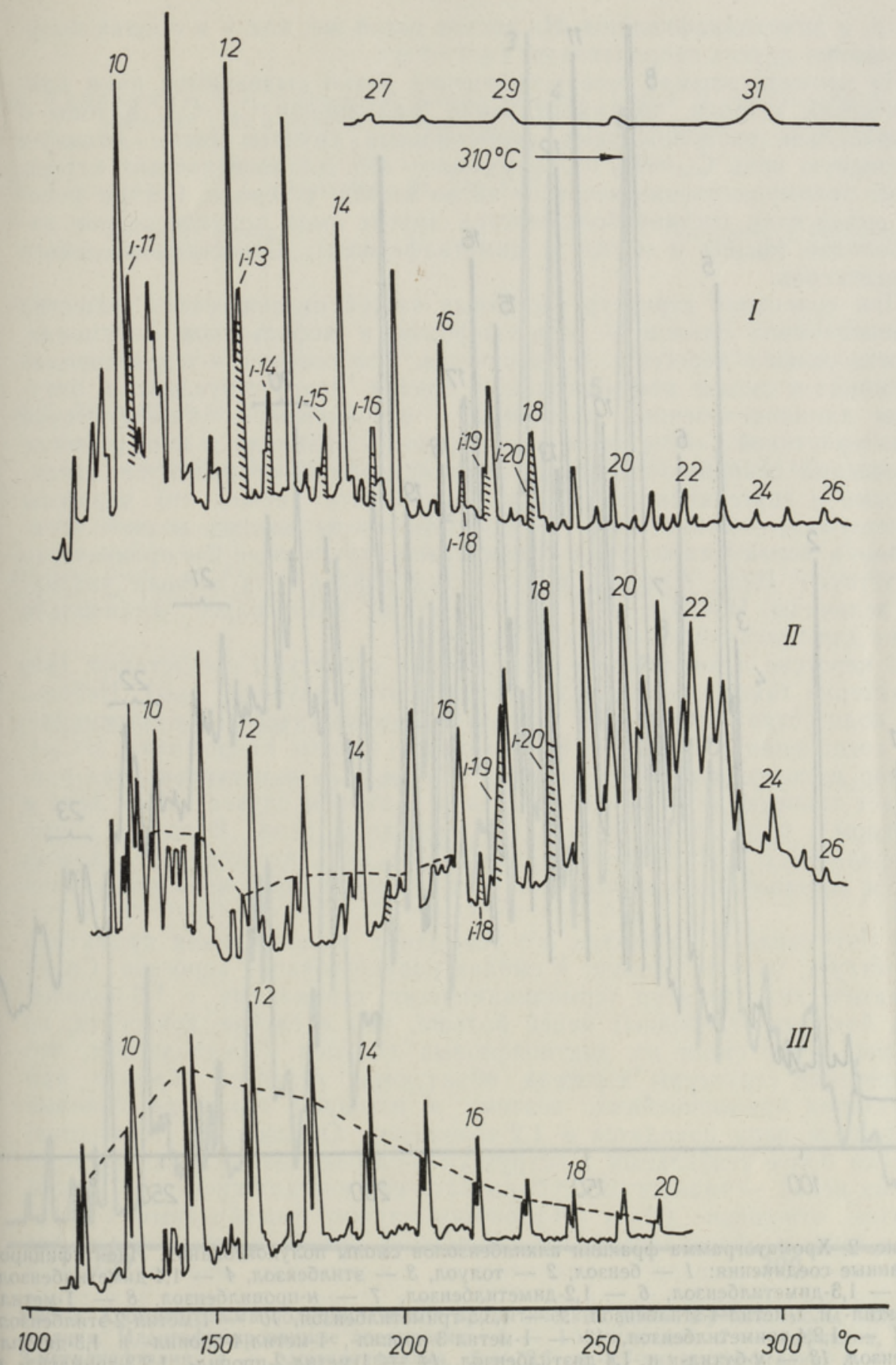

Рис. 1. Хроматограммы фракций алифатических углеводородов, выделенные из: I - битумоида, II - пиролизата асфальтенов битумонда и III - смолы полукоксования дебитуминизированного сланца. Номер пика указывает на количество атомов углерода в соединении $(i-11-i-20-$ изопреновые углеводороды). Пики н-1-олефинов соединены пунктирной линией. Условия хроматографирования: «Хром-4» с параллельными колонками и пламенно-ионизационным детектором, колонки $5,8 м, \varnothing 5 / 3 м \mu, 8 \%$ апиезона $L$ на хромосорбе $P \operatorname{HMDS}$ (45-60 меш.), $4 \%$ мин. 


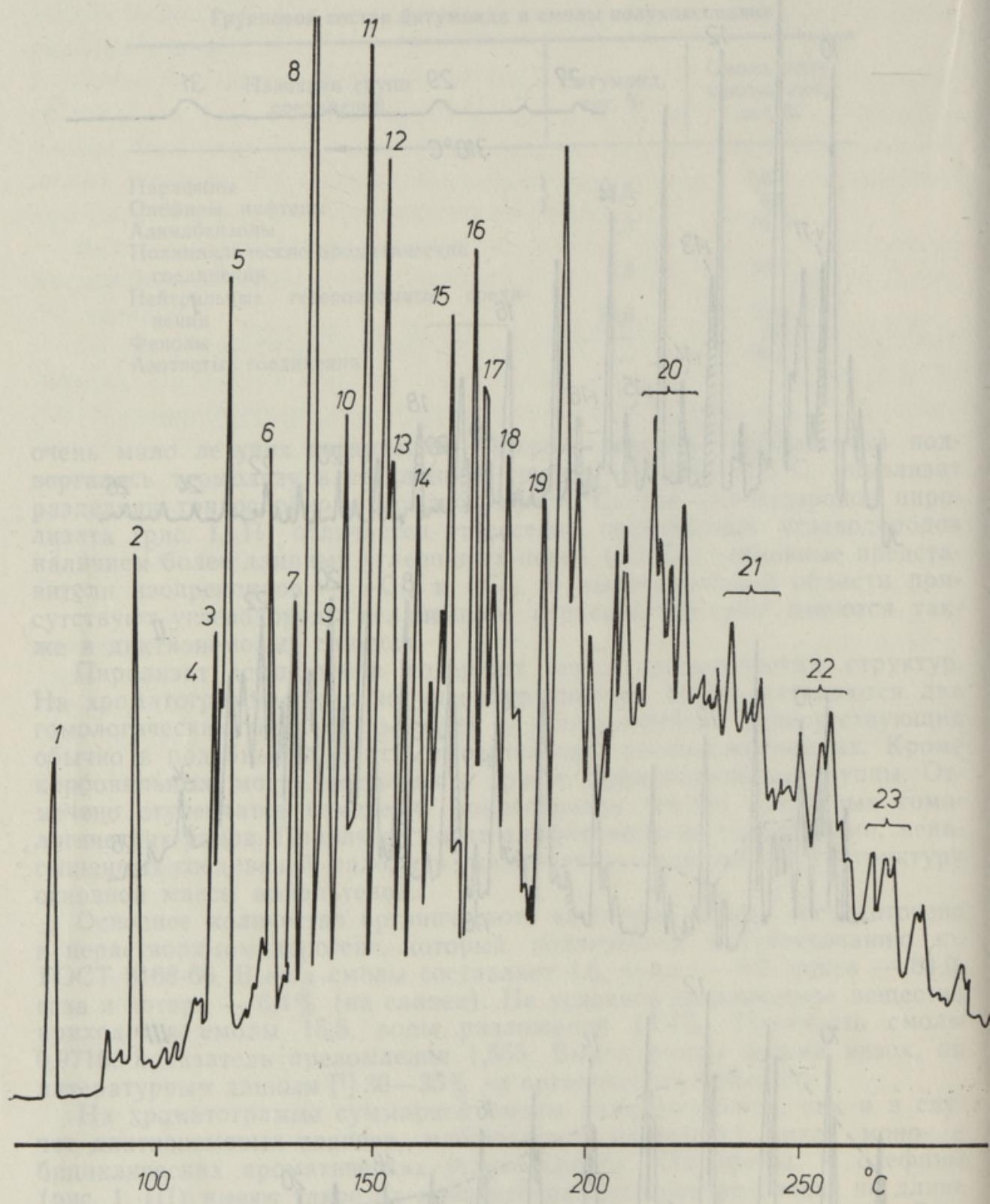

Рис. 2. Хроматограмма фракции алкилбензолов смолы полукоксования. Идентифицированные соединения: 1 - бензол, 2 - толуол, 3 - этилбензол, 4 - 1,4-диметилбензол, $5-1,3$-диметилбензол, $6-1,2$-диметилбензол, $7-\mu$-пропилбензол, $8-1$-метил3-этил- и 1-метил-4-этилбензол, $9-1,3,5$-триметилбензол, $10-1$-метил-2-этилбензол, 11 - 1,2,4-триметилбензол, 12 - 1-метил-3-пропил-, 1-метил-4-пропил- и 1,3-диэтилбензол, 13 - н-бутил- и 1,4-диэтилбензол, 14 - 1-метил-2-пропил-, 1,2,3-триметил- и 1,2-диэтилбензол, 15 - индан, 16 - 1,3-диметил-4-пропил- и 1-метил-3-бутилбензол,

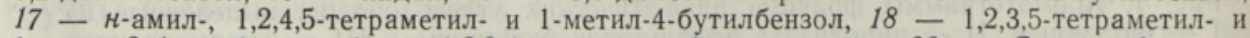
1-метил-2-бутилбензол, $19-1,2,3,4$-тетраметилбензол, инден, $20-\mathrm{C}_{7}$-алкилбензолы,

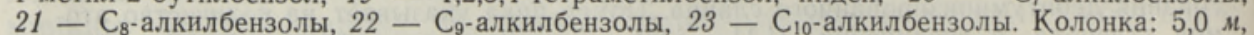
$\varnothing 5 / 3$ мм, $10 \%$ полиэтиленгликоля $40 \mathrm{M}$ на хромосорбе $P, 4 \%$ мин. 
метил- и диметилнафталины. Их состав такой же, как и в смолах полукоксования других сапропелитов.

На хроматограммах гетеросоединений четко выделяются пики алифатических кетонов, преимущественно 2-алканонов $\mathrm{C}_{8}-\mathrm{C}_{15}$. Кетоны с центральным расположением карбонильной группы имеют длинную углеродную цепь $\mathrm{C}_{14}-\mathrm{C}_{16}$. Обнаружено, что длинноцепочные кетоны имеют преимущественно нечетное число атомов углерода. Состав фенолов аналогичен составу большинства других смол полукоксования сапропелитов (фенол и метил- и диметилфенолы). Относительно много ортоизомеров.

При сравнении структур составных частей органического вещества исследованного сланца - углеводородов и асфальтенов битумоида, нерастворимого керогена - выясняется, что составы $\boldsymbol{H}$-углеводородов битумонда и смолы полужоксования близки, присутствующие в битумоиде длинноцепочечные парафины с сохранившейся биологической характеристикой («нечетные»), по-видимому, проникли в породу после завершения основных процессов фоссилизации (они являются аллохтонными и эпигеничными). Следует учитывать также, что керогены раннего палеозоя происходят исключительно из низших водных организмов, в молекулах которых углеродные цепи длиннее $\mathrm{C}_{18}$ практически отсутствуют. Цепи углерода в молекулах асфальтенов длиннее указанной величины. Наблюдаемое несоответствие нами ранее установлено также для булгарийского сланца ТаджССР.

В керогене нециклические изопреновые структуры отсутствуют (это характерно также для других сланцев соответствующей эры). Небольшое количество изопреновых углеводородов присутствует в битумоиде. Эти соединения происходят из фитольной группы хлорофилла $\left(i-\mathrm{C}_{20}\right)$, обычно в седиментах концентрация $i-\mathrm{C}_{19}$ и $i-\mathrm{C}_{20}$ в несколько раз превышает таковую низших членов ряда, а в данном случае имеем дело в основном с продуктами деградации исходной цепи. В то же время в асфальтенах присутствуют только $i-\mathrm{C}_{19}$ и $i$ - $\mathrm{C}_{20}$, что говорит в пользу (как и длинные $н$-алкильные цепи) их происхождения из последующих эпох.

В битумоиде и продуктах его термолиза низкокипящая ароматика отсутствует, но присутствует в смолах полукоксования керогена. Среди ароматических структур термодинамически стабильных с 1,3-положением боковых углеродных цепей больше, чем в случае кукерсита, но меньше, чем в смоле из диктионемовых сланцев. Предполагаем, что циклические структуры керогена образуются главным образом при циклизации прямолинейных, поэтому в исходной структуре боковые углеродные цепи находятся в 1,2-положении. Образование термодинамически более стабильных 1,3-структур - изомеризация боковых углеродных цепей - зависит от глубины катагенетических процессов. Таким образом, отношение 1,2- и 1,3-изомеров служит своеобразным показателем глубины фоссилизации (углефикации). Необходимо отметить, что в молекулах терпенов - циклических соединениях непосредственно биологического происхождения - боковые углеродные цепи находятся в 1,3-положениях (терпены продуцируются высшими растениями).

Оленёкский сланец имеет близкий к кукерситу и диктионемовым сланцам возраст. По глубине катагенетических процессов, содержанию ароматических структур в керогене он является переходным, подвергшимся более глубоким изменениям, чем кукерсит, но не достигшим такой зрелости, как диктионемовые сланцы. 


\section{ЛИТЕРАТУРА}

1. К а ба нько в В. Я., Оленекский бассейн горючих сланцев. В сб.: Геология месторождений угля и горючих сланцев СССР, 11, М., 1968, с. 545.

2. Д е мокидов К. К., К б б аньков В.Я., Л аз ар енко Н. П., С а в и ки й В. Е., С о бол в в к а я Р. Ф., Тр. Ин-та Арктики, 101 (1959).

3. Klesment, I., J. Chromatog., 91, 705 (1974).
Институт химии
Академии наук Эстонской ССР
Поступила в редакцию 1/XII 1975

I. KLESMENT, Juta RIKKEN, K. UROV, O. EISEN

\section{OLENEKI PÓLEVKIVI ORGAANILISE AINE ISELOOMUSTUS}

Ida-Siberi Oleneki maardla põlevkivi ólisaagis on väike. Bitumoidi ja kerogeeni alifaatsete ahelate koostis on lähedane (pikkus kuni $\mathrm{C}_{18}$ ), bitumoidi asfalteenide ahelad on pikemad (kuni $\mathrm{C}_{23}$ ). Kerogeeni pōhimass on aromaatse struktuuriga, tema fossilisatsioonisügavus on väiksem kui diktüoneemakildal, aga suurem kui kukersiidil.

\section{KLESMENT, JUta RIKKEN, K. UROV, O. EISEN}

\section{CHARACTERIZATION OF ORGANIC MATTER IN OLENYOK OIL SHALE}

Semicoking oil yield from East Siberian shale is low. Aliphatic chains of bitumen and kerogen have a similar composition (length up to $\mathrm{C}_{18}$ ), but the chains in bitumen asphaltenes are longer (up to $\mathrm{C}_{23}$ ). The gross material of kerogen is aromatic, but the extent of fossilization lags behind that of dictyonema oil shale. 